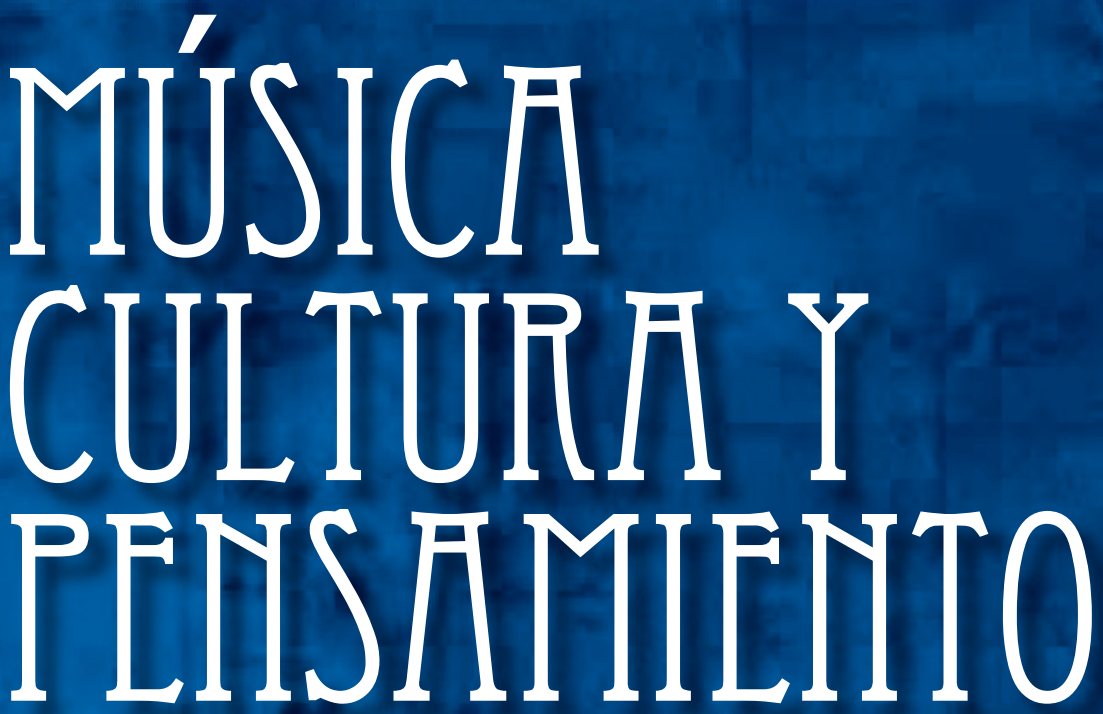

Revista de investigación de la Facultad de Educación y Artes del Conservatorio del Tolima

VOL. VIII N.o 8 - Noviembre 2019
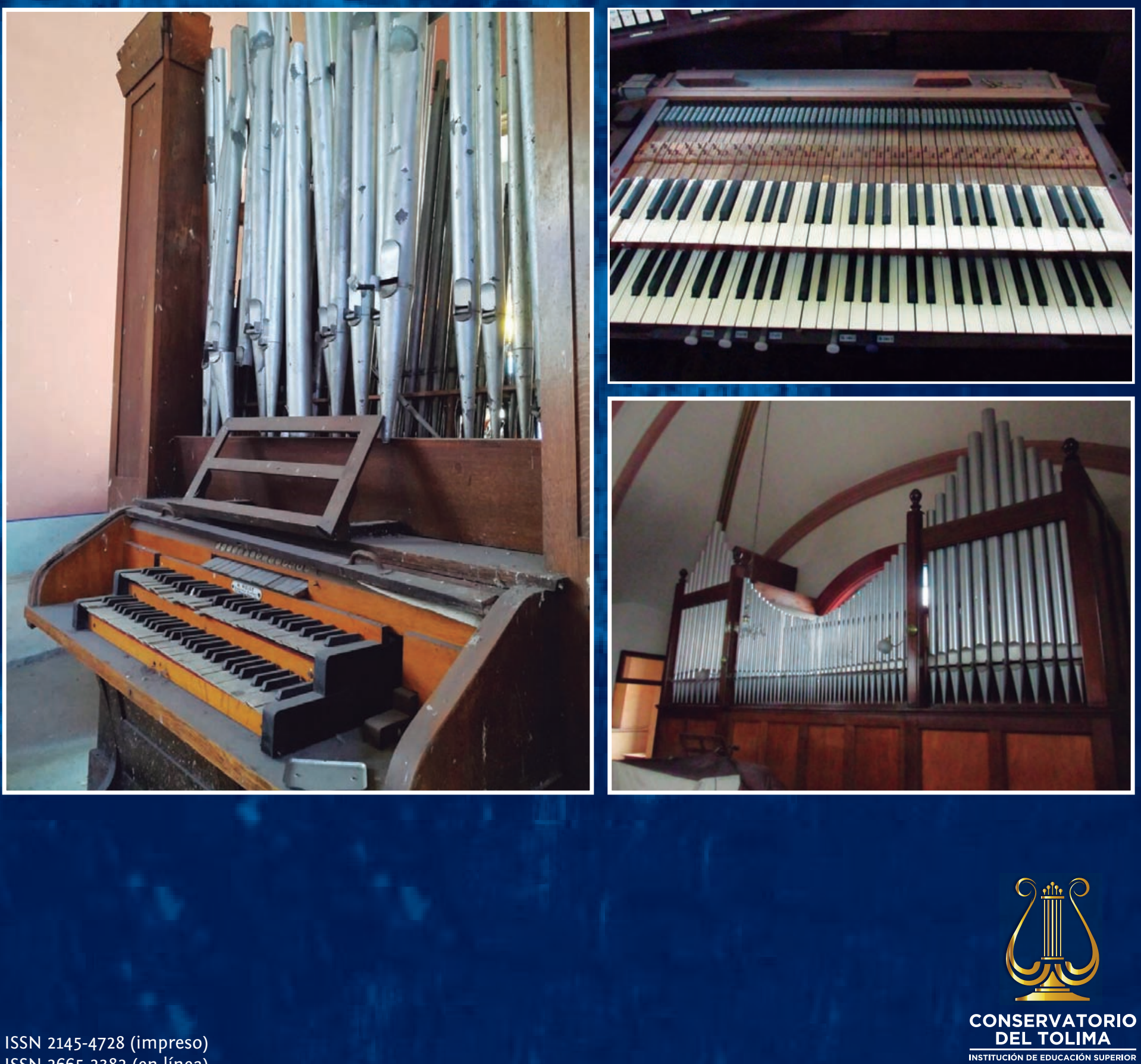


\section{Ecos lejanos de una disputa conceptual: el nacionalismo musical en Nariño}

Por: José Menandro Bastidas España ${ }^{1}$

Artículo de reflexión

Recibido: 15 de junio de 2018

Aceptado: 15 de octubre de 2018

Para citar este artículo/To reference this article: Bastidas, J. M. (2019). Ecos lejanos de una disputa conceptual: el nacionalismo musical en Nariño. Música, Cultura y Pensamiento, 8(8), 25-44.

\section{Echoes far from a conceptual dispute: Musical nationalism in Nariño}

\section{Resumen}

En la primera mitad del siglo XX se produjo una aguda confrontación entre músicos tradicionales y académicos. Esta discusión giró en torno a temas relativos al concepto de la obra nacionalista y, como es de pensar, no encontraron punto de tope. Este fenómeno, al igual que la lucha partidista de liberales y conservadores, tuvo repercusión nacional, alcanzando, incluso, las regiones apartadas como Nariño. En Pasto, Luis E. Nieto, un compositor empírico, buscó sumar su esfuerzo a dicha confrontación y compuso el pasillo Cantar de selva, que es el objeto central de este análisis. En la segunda mitad de la centuria pasada, un grupo de compositores académicos, mejor equipados teóricamente que su antecesor, asumió la tarea de producir repertorios basados en la tradición musical del país, donde la zona andina ya no solo es la única fuente de inspiración, sino también las costas, lo mismo que algunos ritmos suramericanos. Se analiza la información a la luz de los planteamientos de la Historia Nueva, la microhistoria y la hermenéutica gadameriana.

Palabras clave: tradición, música académica, obra nacionalista, vanguardias europeas, identidad.

1 José Menandro Bastidas España, licenciado en Música, especialista en Educación Musical, especialista en Estudios Latinoamericanos y doctor en Ciencias de la Educación. Actualmente es docente del Programa de Licenciatura en Música de la Universidad de Nariño y director del grupo de investigación Grinmus. jotamenandro@gmail.com.

\section{Abstract}

In the first half of the twentieth century, there was an acute confrontation between traditional musicians and $\mathbf{2 5}$ academics. This discussion revolved around issues related to the concept of nationalist work and, as one might 
Ecos lejanos de una disputa conceptual: el nacionalismo musical en Nariño
MÚSICA, CULTURA Y PENSAMIENTO • NOVIEMBRE 2019

VOL. VIII(8) | 25-44. ISSN- 2145-4728; ISSN-E 2665-2382 think, they did not find a point of closure. This phenomenon, like the partisan struggle of liberals and conservatives, had a national impact, reaching, even, the remote regions such as Nariño. In Pasto, Luis E. Nieto, an empirical composer, sought to add his effort to this confrontation and composed the pasillo Cantar de selva, which is the central object of this analysis. In the second half of the last century, a group of academic composers, better equipped theoretically than their predecessor, assumed the task of producing repertoires based on the country's musical tradition, where the Andean region is no longer the only source of inspiration, but also the coasts the same as some South American rhythms. The information is analyzed in light of the approaches of New History, microhistory and gadamerian hermeneutics.

Keywords: tradition, academic music, nationalist work, European avant-garde, identity.

\section{Introducción}

Cuando un investigador busca, en la entraña del tiempo, los hilos que van a - permitirle comprender la realidad del pasado para entender lo que sucede en el presente, se enfrenta a una serie de sinsabores que muchas veces terminan en la frustración y el desencanto. Sin embargo, hay momentos iluminados en los cuales todo se vuelve transparente y el mundo parece cobrar un repentino sentido. Una fotografía, un pedazo de papel con una mancha de tienta, unas palabras garabateadas en la solapa de un libro, una pintura cubierta por el polvo, una partitura amarillenta, un reloj de cuerda que agotó hace décadas su hálito, un palimpsesto que esconde, debajo de un mensaje moral, un poema pagano, se convierten en fuentes insospechadas en el arduo trabajo del que busca. La erudición, propia de los historiadores positivistas del siglo xix, cuyo trabajo consistía en ordenar desapasionadamente los hechos a partir del estudio de las fuentes documentales evitando a toda costa contaminar el material de trabajo con la subjetividad, cambia por completo en la concepción de la Historia Nueva², donde, como primera medida, el valor de los documentos se relativiza y la interpretación del historiador se vuelve relevante. Foucault lo dice claramente:

uno de los rasgos más esenciales de la historia nueva es, sin duda, ese desplazamiento de lo discontinuo: su paso del obstáculo a la práctica; su integración en el discurso del historiador, en el que no desempeña ya el papel de una fatalidad exterior que hay que reducir, sino de un concepto operativo que se utiliza; y, por ello, la inversión de signos, gracias a la cual deja de ser el negativo de la lectura histórica (su revés, su fracaso, el límite de su poder), para convertirse en el elemento positivo que determina su objeto y la validez de su análisis (Foucault, 2010).

Los planteamientos propios de la Historia Nueva y los más recientes de la microhistoria han permitido hilvanar una narrativa respecto de la vinculación de Luis E. Nieto en el nacionalismo musical colombiano, a partir de la composición de su pasillo Cantar de selva. Los enfrentamientos entre músicos tradicionales y académicos alcanzaron los oídos de un compositor empírico en el lejano sur de la República, quien inspirado en la selva del Putumayo y animado por la amistad y la admiración por el apóstol de la música

2 Se habla aquí de la Escuela de los Annales que fuera dirigía por los historiadores franceses Lucien Febvre y Marc Bloch. 
colombiana, Emilio Murillo, produjo una pieza cuyas características contravienen sus preceptos morfológicos más acentuados. A la luz de la argumentación que contiene este trabajo, la obra se ubica en un plano de sentido que no es posible atisbar a simple vista: Nieto buscó los cauces de la confrontación para sumarse a ellos apoyando la tesis de Murillo, tesis en la que sostiene que la obra nacionalista debe, necesariamente, tener profundo arraigo en la música tradicional, aspectos que los académicos, en cabeza de Guillermo Uribe Holguín, no compartían y combatían denodadamente.

Lejos de este enfrentamiento, los compositores nariñenses de la segunda mitad del siglo xx, buscaron recursos formales y expresivos para la estructuración de su trabajo en los viejos anaqueles de una tradición que sufrió marginación una vez se consolidaron el disco y la radio y, con ellos, la música popular comercial. Este fenómeno tuvo gran acogida en todos los estratos de la sociedad colombiana, y, entre otras cosas, permitió un relajamiento respecto de las restricciones morales de la Iglesia católica, impuestas desde la época colonial. Compositores académicos como Justino Revelo Obando (19272000), José Rafael Guerrero (1937), Horacio Mora Ordóñez (1945), Javier Fajardo Chaves (1950-2011), José Alfonso Yépez (1953) y Javier Martínez Maya (1964) se sirvieron generosamente de los ritmos nacionales, especialmente Fajardo Chaves, quien estudió con esmero los aires de la zona andina, pero también los de las costas como el currulao y la cumbia, y algunos suramericanos como el yaraví, el huayno y el sanjuanito, entre otros. Estos ecos tardíos, no fueron precisamente ecos de la disputa conceptual entre tradicionalistas y académicos, fueron resonancias de una necesidad: fundamentar la identidad regional y nacional, identidad diluida en una gran cantidad de sonoridades provenientes de las más disímiles tendencias y generadas en los más voraces intereses económicos.

\section{Ecos tempranos}

El nacionalismo romántico europeo va a tener un reflejo tardío en Latinoamérica, llegará impregnado de la estética sobre la cual creó la gran mayoría de los músicos del siglo xIx, pero también se dejará influir por las vanguardias posrománticas como el Impresionismo francés y el Expresionismo alemán. Los músicos de esta parte del mundo buscarán con denuedo herramientas en estas corrientes, pero volverán los ojos hacia aquello que era la expresión de sus particularidades: la música popular, la tradicional y la ancestral. Sobre la base de estos elementos, los compositores académicos lograron plasmar un conjunto de obras que hoy son evidencia de un momento en el que el continente soñó con entrar en el decurso histórico de la música trazado por Europa. Pero el panorama relativo a la expansión de este nacionalismo en Latinoamérica es variopinto, esto es, se manifestó de diversas formas y en diferentes momentos, circunstancia que estuvo determinada por el avance cultural de los países que conforman el continente y en el que se presentaron, de manera recurrente, las confusiones de tipo conceptual.

En Colombia, el desarrollo del nacionalismo estuvo cruzado por una discusión acalorada respecto de si la obra nacionalista debía tener relación con las inherencias musicales del país o ser la expresión pura del ejercicio creativo del compositor. Quienes defendían la música tradicional como la expresión más definida de la obra nacionalista, formaron un frente de defensa y ataque contra los académicos que no reconocían mayor valor estético en estas expresiones. En este vaivén de imprecaciones se produce en el sur del país el pasillo Cantar de selva, compuesto por Luis Enrique Nieto (1898-1968) en 1937, (véase figura 1) cuando vivió en la entonces comisaría del Putumayo; es una obra extraña al contexto general de su trabajo y por ello llama la atención y motiva este análisis.

3 Luis E. Nieto nació el 21 de junio de 1898 en Pasto; sus padres fueron Manuel Nieto y Antonia Sánchez. En 1905 ingresó a estudiar al Instituto Champagnat de los hermanos maristas donde hizo parte del coro. En 1912, cuando contaba apenas con 14 años de edad, compuso su primera pieza, Mentiras de un músico, tras la cual seguiría una amplia producción entre la que se destaca el bambuco Chambú, el pasillo Valle del Cauca, la danza Ruego y el fox-trot Viejo dolor, entre otros. A lo largo de sus 70 años de edad trabajó en pro del desarrollo y difusión de la música tradicional de la zona andina colombiana. Fundador de la Lira Clavel Rojo, agrupación con la que se dio a conocer nacionalmente. Murió en Pasto el 23 de diciembre de 1968. 
Ecos lejanos de una disputa conceptual: el nacionalismo musical en Nariño
MÚSICA, CULTURA Y PENSAMIENTO • NOVIEMBRE 2019

VOL. VIII(8) | 25-44. ISSN- 2145-4728; ISSN-E 2665-2382

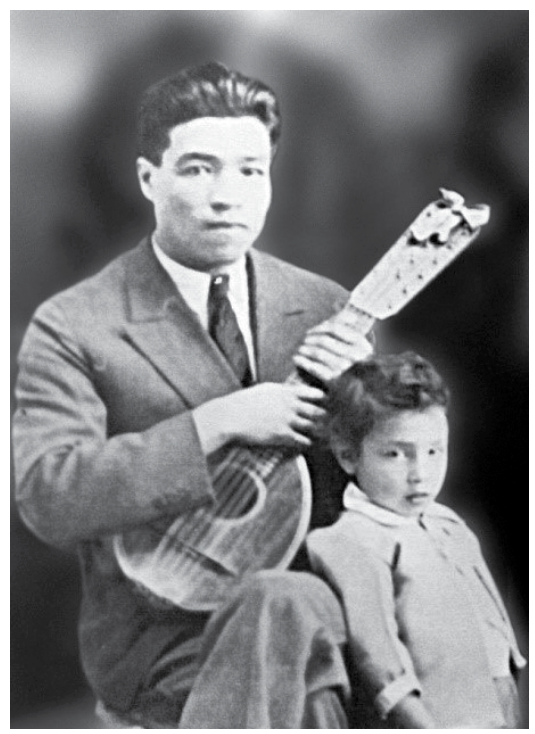

Figura 1. Luis Enrique Nieto en compañía de uno de sus hijos, hacia 1930

Fuente: Revista llustración Nariñense, No. 40 serie iv, febrero de 1931.

De los manuscritos de las obras de Nieto se conservan 64 piezas, entre las que predominan los ritmos de pasillo, marcha y bambuco; en menor proporción se encuentran danzas, valses, fox-trots, boleros, pasodobles y un bunde. Su tendencia a favorecer la tradición musical lo llevó a enfatizar en los tres primeros ritmos mencionados. El vals y el pasodoble también formaban parte de dicha tradición, pero su demanda, debido a los nuevos influjos, ya había decaído en la primera mitad del siglo xx, de ahí su escasa producción. Como caso aislado, puede notarse la presencia de un bunde ${ }^{4}$, muy esporádico en la composición nariñense, lo que obedece a la intención de Nieto por relacionar la música nariñense con la andina nacional y alejarla del espíritu melancólico de las tonadas ecuatorianas, espíritu con el que se ha asociado históricamente esta música; sin embargo, su baja producción denota la poca aceptación que tenía el bunde entre los meridionales, cuyos gustos estaban inclinados, en su amplia generalidad, hacia la música del vecino país.

En cuanto al conocimiento de las formas musicales tradicionales, sobre las cuales compuso sus obras, se presentan dos situaciones: la generalidad conserva su estructura característica en cuanto a sus partes constitutivas y al número de compases que las integran $^{5}$; sin embargo, resulta frecuente encontrar

4 El bunde es un aire característico del Tolima Grande, actuales departamentos del Tolima y Huila.

5 Forma tripartita con 16 o 32 compases cada parte, períodos de ocho compases y frases de cuatro. pasillos y danzas que abandonan por completo este esquema. En algunos casos, esto obedece a la falta de simetría de los textos poéticos sobre los cuales compuso sus canciones y, en otros, a necesidades propias de la estructura melódica. Los giros armónicos que utilizó con mayor frecuencia se relacionaron con las tonalidades menores de $D, E, A, G$ y $C$ para pasillos, bambucos y danzas; y D, F, C, A, G y Bb mayores para marchas, pasodobles, fox-trots y valses.

En la generalidad de las obras utiliza el manido recurso de la música andina colombiana: el círculo de la tonalidad de Re menor ${ }^{6}$, pero también recurrió al uso frecuente de interdominantes, que le posibilitaban ir transitoriamente a otras tonalidades y lograr cambios de color y mayores posibilidades melódicas. También es frecuente el uso de acordes disminuidos con funcionalidad de dominante, que crean un interesante efecto de inestabilidad momentánea, lo que puede apreciarse en obras como la danza Canción tumaqueña, el bambuco Ñapanguita soy y la marcha Pazizara, entre otras. Sin embargo, si las obras de Nieto configuran un corpus más o menos homogéneo desde la funcionalidad armónica y temática, el pasillo Cantar de selva se aparta por completo de todo esquema; según sus propias palabras, la belleza de la selva amazónica le inspiró la mencionada obra, además del vals Mirando al Putumayo ${ }^{7}$.

Cantar de selva (véase anexo 1) es un pasillo de tres partes, con 23, 17 y 23 compases, respectivamente; escrito en formato pianístico y que, por la disposición de las voces en las claves de sol y fa, puede decirse que se transcribió para ser interpretado con este instrumento. La armadura en la que define el centro tonal es la de mi menor; sin embargo, el juego armónico interno, en el que predominan los acordes disminuidos, se aleja por completo del tratamiento convencional presente en sus restantes obras. Tampoco posee la estructura de acompañamiento propia de este ritmo, observable en otros pasillos de su producción. La primera parte inicia con un melisma ascendente sobre la tonalidad axial, que combina intervalos de quintas y sextas paralelas, ascenso interrumpido abruptamente por la aparición de un calderón, que frena la idea melódica.

6 Dm A7 Gm Dm A7 Dm.

7 La Autobiografía, de Luis E. Nieto, es un manuscrito que reposa en los archivos del Centro de Documentación Musical de la Biblioteca Nacional. 
En seguida, expone un motivo rítmico con armonía alterada, donde combina los grados primero y quinto con una secuencia de acordes disminuidos; en el sexto compás, presenta un melisma similar al inicial, pero, en esta ocasión, en el axial mayor, seguido por el mismo motivo rítmico que le antecede. La incoherencia armónica de este tracto lleva a pensar que se cometieron errores de transcripción, toda vez que este trabajo lo realizaba una tercera persona, generalmente, Gonzalo Moreno; la secuencia de los acordes podría cifrarse, aproximadamente, del siguiente modo: G\#dis F\#m7 G\#dis E\#dis A\#dis Bm G\#m Am G\#m Am.

Los subsiguientes compases de la primera parte discurren sobre bloques rítmicos en paralelo en el mismo ambiente armónico alterado, con predominio del acorde de D\#dis que, en algunos casos, el compositor utiliza con función de dominante respecto de mi menor. Dichos bloques son un recurso del que se sirve generosamente en cada una de sus tres partes constitutivas, lo mismo que del acorde arpegiado; este último lo expone en corcheas, en semicorcheas y en tresillos de semicorcheas, quizá con el propósito de darle dramatismo y dinamismo a la obra.

¿Por qué Nieto, un compositor tan tradicionalista, compondría una pieza como Cantar de selva? Un músico empírico como él, se abocaba a la composición tradicional por el horizonte histórico que le precede. Luis E. Nieto representa la tradición cultural proveniente del siglo xıx. No obstante, haber nacido en las postrimerías de dicho siglo, heredó toda la carga ideológica de una sociedad señorial orgullosa de su raza, de sus apellidos ibéricos, de sus blasones, de la religión católica y, obviamente, del Partido Conservador. En su bambuco Soy pastuso ${ }^{8}$, expresa la concepción de ese pasado que aún gravitaba en el espíritu de su época, un espíritu generado en los atavismos coloniales con una fuerte dosis de realismo y religiosidad católica. Para esta concepción, Pasto era la Esparta de la Nueva Granada, la ciudad que había luchado, casi hasta la extinción, por defender su devoción, sus juramentos de lealtad, su raza, su tradición, su herencia.

Aunque Nieto vivió en la época de los nuevos influjos musicales provenientes de las Antillas y de la Costa Caribe, en especial los de Pacho Galán y Lucho

8 "Soy pastuso de tierra noble, /Tierra heroica donde nací. /Su raza llevo dentro la sangre, /Sangre de fuego y de tradición. /Escudo de armas de la nación /San Juan de Pasto, ciudad leal, /Fecunda entraña de la canción, /Ciudad espartana, la muy leal". Texto tomado de Bastidas (2014).
Bermúdez, su trabajo no muestra signos de haberse dejado influir por ellos, todo lo contrario, en su autobiografía muestra una clara aversión hacia el fenómeno de la música caribeña. Las obras que compuso se inscriben en las formas características de la tradición decimonónica (pasillo, danza, marcha, pasodoble, vals, bambuco). De la nueva música, solo se permitió licencia para componer unos cuantos boleros y otros tantos fox-trots, entre los cuales el más conocido es Viejo dolor. Este es un claro signo de resistencia frente a la corriente de la música comercial que difundía la radio y que terminó por marginar la tradición, no solo en Nariño, sino también en todas las regiones del mundo. Muchos compositores locales y nacionales mostraron igual actitud frente a este fenómeno, situación que los condenó a la casi completa invisibilidad.

El grueso del trabajo creativo de Nieto muestra congruencia con los preceptos de ese entorno discursivo, en el cual no se inscribe Cantar de selva. Hay dos explicaciones posibles que justifican la existencia de este pasillo: la primera, se relaciona con las recriminaciones de sus detractores respecto de su condición musical empírica y, la segunda, en la necesidad de apoyar el movimiento nacionalista liderado por su amigo Emilio Murillo (véase figura 2), el cual recibía ataques desde muchos frentes. Sin embargo, las dos situaciones pueden correlacionarse, porque estos músicos sintieron, en niveles diferentes, el rigor del asedio y la descalificación de los músicos académicos.

En el primer caso, el pasillo Cantar de selva es la confirmación de su frase Yo no sé nota, pero no se nota. Este enunciado encierra distintas capas de sentido: afirma un estado de la propia condición, pues evidencia una carencia: no conocer el código de escritura musical, lo que torna manifiesto su empirismo y la falta de estudios académicos. Sin embargo, la aceptación de esta circunstancia se equilibra cuando afirma categóricamente que esa carencia no se nota y, al afirmarlo, expresa la solvencia alcanzada en el trabajo creativo e interpretativo: compuso 27 pasillos, 23 marchas, 15 bambucos, 9 danzas, 7 valses, 5 fox-trots, 5 boleros, 6 himnos, un pasodoble y un bunde ${ }^{9}$, e interpretaba instrumentos como el

9 Hay quienes afirman que la obra de Nieto supera las trescientas piezas; sin embargo, este dato no ha podido ser confirmado, puesto que no hay evidencia de las restantes obras que, sobre la base de este supuesto, serían más de doscientas. Es probable que muchas no fueran transcritas y descendieran a la tumba con él. Es conveniente aclarar que de estas 99 obras que ha sido posible enlistar, solo 64 se conservan en partitura. 
Ecos lejanos de una disputa conceptual: el nacionalismo musical en Nariño
MÚSICA, CULTURA Y PENSAMIENTO • NOVIEMBRE 2019

VOL. VIII(8) | 25-44. ISSN- 2145-4728; ISSN-E 2665-2382 requinto, la guitarra, el guitarrón, el banjo, el tiple, la mandolina y el laúd. Muchas de sus obras, entre ellas el bambuco Chambú, han trascendido los límites de su tierra natal.

No conocer la notación musical es una situación que ubica al músico empírico en una condición de inferioridad respecto del músico de escuela. Hay testimonios en los que es posible evidenciar una fuerte tensión entre quienes conocían la notación y aquellos que no la conocían. Luis el Chato Guerrero (1916-2011 $)^{10}$ afirmaba que algunos de los músicos de escuela, en un gesto de abierta discriminación, los calificaban, a él y a Nieto, como músicos "orejeros". El Chato, desde su jovialidad característica, señala que les contestaba: "y ustedes, maestros, ¿con qué oyen la música?" 11 . Sin embargo, esta situación estableció una honda brecha entre músicos de atril y músicos empíricos, que muchas veces resultó insalvable. Lo curioso del caso es que quienes proferían ese tipo de ofensas eran músicos populares, cuya única diferencia era el conocimiento del código de escritura musical ${ }^{12}$.

En esta confrontación, la frase de Nieto cobra otro plano de sentido. Dicho entre músicos de la misma condición, la frase objeto del análisis reivindica su empirismo y su "analfabetismo" musical, para utilizar las palabras de Justino Revelo Obando ${ }^{13}$; emitido en presencia de sus detractores, asume otra dirección: Ustedes saben nota, pero no se nota, lo que constituiría una recriminación relativa a la calidad de su creación e interpretación. Esto se justifica por cuanto el peso histórico de la academia en Pasto no fue congruente con sus derivas en el campo de la producción musical ${ }^{14}$. Resulta claro que saber

10 Luis el Chato Guerrero nació en Pasto el 30 de julio de 1916, a lo largo de sus 95 años de edad se dedicó al cultivo de la música tradicional, especialmente el bambuco, entre los que se destacan: Agualongo y Cachirí. También dedicó algunas de sus más importantes piezas a los ritmos provenientes de la música tropical como el merengue Cuando tú me quieras y los paseos Te adoro mujer y Así será. Murió en Pasto el 13 de octubre de 2011.

11 Entrevista a Luis Antonio el Chato Guerrero.

12 Refiere el Chato Guerrero que muchos de los músicos que más criticaban su empirismo y el de Nieto interpretaban y componían música inscrita en la tradición popular andina colombiana, ámbito en el que los dos eran reconocidas autoridades.

13 Justino Ernesto Revelo Obando (Puerres 1927-Pasto 2000) fue un músico académico, que dejó una producción considerable en el campo de la polifonía; fue rector de la Universidad de Nariño y director de coros por muchos años; con frecuencia utilizaba esta frase para referirse a los músicos empíricos.

14 Aquí se hace referencia a la Escuela de Música de la Universidad de Nariño que tuvo vigencia entre 1938 y 1965, cuyas derivas en el campo de la composición académica es tabula rasa. No obstante, y es preciso decirlo, su acción educativa notación no hace que un músico sea compositor, como tampoco que este conocimiento sea condición sine qua non para la creación, los músicos populares lo demuestran permanentemente. Para la composición académica, la situación resulta diferente, porque no es posible transmitir por tradición oral, por ejemplo, la música sinfónica, sin que se pierdan en el proceso parte de sus componentes.

Cantar de selva podría interpretarse como una respuesta a los muchos detractores que tuvo Nieto, porque sus condiciones formales se alejan de la tradición y se acercan a la academia. Con este pasillo el compositor quiso, quizá, demostrar su habilidad en este ámbito, pero su esfuerzo no vio resultados, ya que no se conoce que esta obra fuera interpretada en su tiempo.

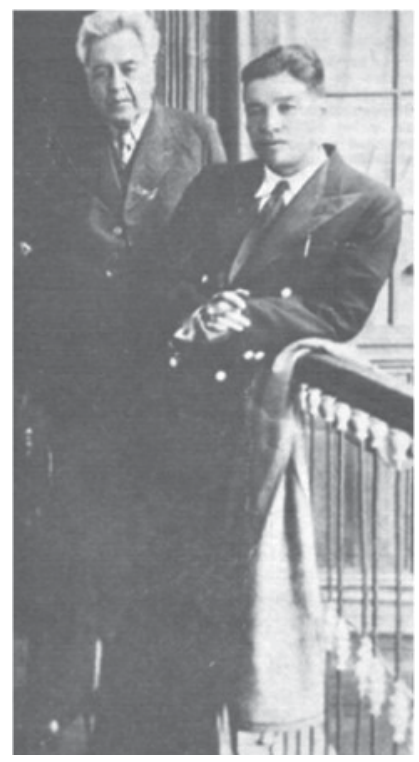

Figura 2. Emilio Murillo y Luis E. Nieto, hacia 1938 Fotógrafo desconocido. Fuente: Roberto Nieto.

Para que se pudiera presentar la segunda posibilidad, es necesario, primero, comprender la situación de la producción de Emilio Murillo (1880-1942) ${ }^{15}$, sobre todo aquella que se relaciona con su obra pianística tardía. Murillo era asiduo defensor de la tradición

permitió a muchos músicos cualificar su trabajo en los ámbitos tradicional y popular.

15 Emilio Murillo Chapul nació en el municipio de Guateque, Boyacá, el 9 de abril de 1880. Estudió en la Academia Nacional de Música y fue experto flautista, tiplista y pianista. Fue discípulo de Pedro Morales Pino, uno de los más importantes representantes de la música de los Andes nacionales. Murillo fue llamado el apóstol de la música colombiana por su defensa y cultivo de los aires tradicionales. Fundó su propia agrupación, la Estudiantina Murillo, con la cual difundió los repertorios de muchos compositores y la suya. Murió en Bogotá el 9 de agosto de 1942. 
musical decimonónica, en la que inscribió casi todo su trabajo, al igual que Nieto; pero, a diferencia de este, el compositor guatecano no era empírico, pues había realizado estudios en la Academia Nacional de Música, donde tomó clases de flauta y piano, por lo que puede afirmarse que tenía una buena cimentación en la teoría musical. No obstante, esta circunstancia, no resulta posible afirmar que Murillo fuera un compositor académico, en la acepción occidental de la expresión.

Murillo lideró un movimiento en favor de la música tradicional colombiana, en reacción a los ataques y descalificaciones del compositor Guillermo Uribe Holguín (1880-1971) ${ }^{16}$. Desde el punto de vista de la cobertura nacional y teniendo en cuenta la dificultad de acceder a las regiones apartadas, los alcances de dicho movimiento fueron grandes. La fotografía adjunta es una muestra de lo dicho; su fecha probable es agosto de $1938^{17}$, año en el que se celebraron los 400 años de la fundación de Bogotá. Para esta memorable efeméride, el gobierno distrital invitó a muchas agrupaciones musicales de diferentes regiones del país, entre ellas la Lira Clavel Rojo, el grupo que fuera la bandera musical de Nieto. En su autobiografía, este compositor refiere que interpretó, entre otras obras, su bambuco Ñapanguita soy, sobre el que Murillo dijo ser "el monumento a la raza"18.

La confrontación entre académicos y tradicionales se centraba en la discusión sobre la obra nacionalista, enfrentamiento que se dio en medios escritos y radiales con utilización, muchas veces, de un lenguaje

16 Guillermo Uribe Holguín nació en Bogotá el 17 de marzo de 1880. Inició sus estudios musicales en la Academia Nacional de Música bajo la tutela de Santos Cifuentes. Posteriormente, hizo su ingreso a la Schola Cantorum de París donde el músico impresionista Vincent d'Indy fue uno de sus más importantes profesores; se graduó de esta escuela en 1910, en el tiempo récord de tres años. Regresó a Colombia y convirtió la academia mencionada en lo que hoy se conoce como el Conservatorio Nacional. Creó la Sociedad de Conciertos, la que contaba con una orquesta, que sería la base de la Orquesta Sinfónica de Colombia. Su trabajo como compositor es prolífico, en él se destacan la música pianística, sus once sinfonías, sus poemas sinfónicos, los cuartetos de cuerda, las obras para solista y orquesta, el drama lírico Furatena y una amplia variedad de repertorios de música de cámara.

17 Hacia 1938, la ciudad de Pasto seguía siendo una ciudad marginal, a la que era muy difícil llegar debido a la precariedad de las vías de acceso y a los peligros que en ellas acosaban a los viajeros, circunstancia que limitaba la relación entre los meridionales y los habitantes del centro del país; pese a estas circunstancias, Nieto y Murillo mantenían una relación de amistad que favorecía a los dos músicos y que se basaba en sus hondas convicciones relativas a la tradición. 18 Nieto, Autobiografía. altisonante. A la obra nacionalista, desde el parecer del músico popular, la representaba la música tradicional colombiana, encabezada por el bambuco. Sin embargo, la consideración de los académicos apuntaba en dirección opuesta. Mario Gómez-Vignes dice que, para Murillo, “... el enaltecimiento de la música colombiana consistía en orquestar para sinfónica bambucos, pasillos y cumbias creyendo que con ello se les otorgaba cédula de ciudadanía internacional" (Gómez-Vignes, 1991). Valencia, por su lado, consideraba que

[...] la música nacional no existe porque haya tal o cual tema melódico o ritmo que se considere criollo. Eso es lo de menos. Existirá necesariamente cuando haya compositores que, educados en el estudio de las obras universales, dejen verter su inspiración en las obras que su corazón les dicte sinceramente. La música nacional está en el ambiente y el músico será por fuerza músico nacional, como lo son los grandes compositores de todos los países [...] Yo estimo que no existe música nacional, existe únicamente música popular; la música nacional -que dignifica y eleva al pueblo- no consiste solamente en los temas populares, sino que en ella el compositor debe compenetrarse con la naturaleza, con el ambiente que lo rodea, y realizar una obra personal y autónoma. Siguiendo estas huellas es la única forma de llegar a tener música nacional (Gómez-Vignes, 1991).

Un poco en contravía de su propio criterio, resulta curioso encontrar elementos de la música tradicional colombiana en obras como Chirimía y Sotareño, Pasillo (C. G-V 8) ${ }^{19}$, el pasillo Palmira, Pasillo No. 4, Bambuco "del tiempo del ruido", Sonatina boyacense, entre otras. En la primera obra, toma El sotareño, bambuco compuesto por Francisco Diago ${ }^{20}$, y con él efectúa precisamente lo contrario de lo que pregonaba: vestirlo con ropaje académico, lo cual, lejos de enaltecerlo, lo caricaturiza. Por tradición oral, se conoce que Diago reaccionó con desagrado cuando

19 Nomenclatura de la catalogación de Mario Gómez-Vignes, en su libro Imagen y obra de Antonio María Valencia (1991).

20 El Sotareño lo compuso, hacia 1928, Francisco Eduardo Diago, a partir de un tema tradicional de la región de Sotará, al que, al parecer, le añadió la sección final. A este bambuco lo consideran el himno del municipio homónimo; en torno a él, se han organizado eventos culturales, como el Concurso del Bambuco Sotareño, liderado desde 1997 por la Institución Educativa La Paz, y el encuentro "Inter-étnico departamental del baile del bambuco Sotareño", cuya primera versión fue en 2012 
Ecos lejanos de una disputa conceptual: el nacionalismo musical en Nariño
MÚSICA, CULTURA Y PENSAMIENTO • NOVIEMBRE 2019

VOL. VIII(8) | 25-44. ISSN- 2145-4728; ISSN-E 2665-2382 escuchó, de manos de Valencia, la interpretación de su estilización de $E /$ sotareño ${ }^{21}$.

En la obra de Uribe Holguín, también pueden apreciarse elementos de la tradición que dejan una sensación de ambigüedad respecto de sus preceptos fundamentales sobre la música popular, pues su discurso descalificador supondría un alejamiento total de lo vernáculo:

[...] hay quienes consideran que poseemos ya un arte nacional; están en un error, proveniente de la confusión que hacen entre arte nacional y arte popular. [...] Por un efecto de mal gusto, generalmente producto de la ignorancia, el falso arte se propaga con sorprendente facilidad" (Cortés, 2004) ${ }^{22}$.

Una obra en la que Uribe Holguín introduce elementos de la tradición es el Ballet Criollo No. ${ }^{23}$, puesto que en ella existe una evidente evocación del torbellino El guayatuno, de Efraín Medina Mora (1924-2008), canción de honda raigambre campesina. Algo similar puede apreciarse en la Sinfonía No. 2 "Del terruño", Op. 15a (1924), en la cual pueden identificarse elementos de la tradición musical colombiana. Respecto de esta obra, se dice que, tal vez, se escribió

[...] con el ánimo de demostrar que su propuesta como compositor no tenía por qué anular elementos de inspiración colombiana, la Sinfonía del Terruño acogía elementos programáticos y alusiones rítmicas que, en medio de un lenguaje sinfónico heredado de su maestro Vincent d'Indy, resultaba en una obra digna de ser catalogada bajo el rótulo de "música nacional" (Mesa, 2013).

Murillo y Uribe Holguín se encontraban en polos extremos, cada cual defendiendo lo que consideraban correcto, en congruencia con su horizonte histórico. Los dos músicos, sin embargo, van a tener un punto en común que no produjo acercamiento

21 Luis Ospina, Antonio María Valencia: música en cámara (s.f.). En este trabajo de video, sobre la vida y obra del compositor caleño, el pintor Jesús María Espinosa afirma que Francisco Diago, después de escuchar la versión, le dijo: "Te tiraste mi bambuco". Cfr., Ospina, L. (s.f.).

22 En este libro se cita un artículo de Uribe Holguín publicado por la Revista del Conservatorio Nacional titulado "Triunfaremos". La palabra, en apariencia intrascendente, encierra un marcado interés en desterrar toda sombra de la música popular en la producción académica.

23 Puede escucharse en línea. https://www.youtube.com/watch?v=2jcdqafiddm. personal pero que dejó un interesante resultado. Murillo, desde la expresión de lo que fue su producción musical de juventud, recibió aplausos, pero también muchas críticas, puesto que se desconfiaba de su capacidad como compositor: Luis Miguel de Zulategui (1889-1970) y Gonzalo Vidal (1863-1946), sus más acérrimos contradictores en Medellín, lo consideraban un compositor mediocre (Santamaría, 2014). Vidal se expresaba en estos términos sobre Murillo: "[un compositor] sin estudios serios, sin habilidad siquiera para confeccionar pasillitos, dancitas, guabinillas, bambucos, mucho menos para explotar obras y producir obras de arte sólido"24 (Santamaría, 2014, p. 73). Las razones de esta estigmatización se basaban en el hecho de que, al parecer, Murillo se interesaba más en la cantidad que en la calidad; además, su abierto gobiernismo chocaba en los círculos intelectuales y sociales de dicha ciudad, dadas las diferencias políticas que la capital antioqueña tenía con Bogotá. Esta circunstancia llevó al guatecano a componer repertorios con características académicas, alejados de sus obras anteriores, aquellas que transpiraban un bucolismo anhelado por muchos, entre ellos Perdomo Escobar.

[...] las composiciones de Murillo son tanto más bellas, sentidas y hermosas, cuanto más sencillas. Las que escribió en su juventud tienen un aroma de campo, huelen a poleo y albahaca, tienen el olor de la miel del trapiche. Los estudios posteriores pecan por forzados y faltos de originalidad; no ostentan la fragancia de aquellos de antaño (Perdomo, 1980).

Entre las primeras obras se cuentan: El trapiche, Canoíta, El guatecano, Cachipay, Yo me muero de amor, Canción de la tarde, Lucero, Morenita, Golondrinas, Rumichaca, Hondos pesares, Fiebres y La cabaña. Entre los estudios posteriores, a los que se refiere Perdomo, están muchos de los pasillos para piano, como los Nos. 1, 2, 3, 6, 7, 8, 9, 10, 11, 12 y $14^{25}$. Resulta un poco exagerado afirmar que la música en mención careciera de originalidad; esta afirmación solo evidencia un sesgo condicionado por la

\footnotetext{
24 Texto citado por Carolina Santamaría de un escrito de Gonzalo Vidal, El caso musical, publicado por el Heraldo de Antioquia, 9 de abril de 1928, p. 2.

25 Banco Virtual de Partituras - Biblioteca Nacional de Colombia, http://www.bibliotecanacional.gov.co/partituras/ (consultado el 17 de noviembre de 2014). En esta dirección, en el link de compositores centenaristas, pueden encontrarse las partituras de muchas de las obras de Murillo, incluidos sus pasillos numerados, por llamarlos de algún modo.
} 
tradición. Quizá Perdomo tenía razón cuando decía que dichos estudios eran forzados, porque, en cierta medida, lo son; no en el sentido de que congreguen un conjunto de fuerzas dispersas en medio de una emocionalidad y una estética confusas, sino en el sentido de que su existencia obedece a la manifestación de fuerzas externas antagónicas, producto de la violencia desplegada desde los centros del poder-saber, representados por los conservatorios Nacional y de Cali, canal por el cual se reprodujo en Colombia la visión excluyente del Viejo Continente.

En estas obras, es posible notar el afán de Murillo por estilizar el pasillo y diluir, en un juego melismático, sus componentes rítmicos característicos. Está claro que no se compusieron para ser interpretadas por músicos empíricos, sino por las manos de pianistas de escuela. El uso de tonalidades y giros armónicos, poco frecuentes en la música tradicional, hacen de este conjunto de obras algo de difícil acceso para quienes se hallaban al margen de la academia. Tal vez Murillo quiso producir una obra que pudiera oír, en las salas de concierto, un público cultivado en la escucha de los repertorios clásicos, quizá, junto a los 300 trozos en el sentimiento popular, de Uribe Holguín, trabajo en el que también se observa una intención de estilización de los ritmos populares (Duque, 1980), producido entre 1928 y 1939, época muy cercana con el trabajo de Murillo y cuya construcción estuvo originada en móviles similares a los del compositor guatecano: la presión de sus coterráneos ${ }^{26}$.

Uribe Holguín, por su parte, sufrió el rechazo de una sociedad que no estaba preparada para escuchar su música. Habiendo bebido directamente de las corrientes vanguardistas europeas, su trabajo no pudo menos que reflejar este influjo y producir una obra de difícil escucha, toda vez que muchos de sus compatriotas miraban la música desde el canon clásico-romántico y consideraban los ritmos tradicionales como el único fundamento de la música nacional. Para comprender un poco la intención de Uribe Holguín, solo basta con escuchar la Sinfonía No. 1 en $\mathrm{fa} \mathrm{menor}^{27}$; el lenguaje novedoso de esta obra difícilmente tendría acogida en el medio cultural bogotano, ni qué decir de otras ciudades del país. La constante recriminación sobre la carencia

26 Los 300 trozos en el sentimiento popular, de Uribe Holguín, se compusieron entre 1927 y 1939 , y los pasillos numerados de Murillo, aproximadamente entre 1929 y 1931.

27 Disponible en línea: https://www.youtube.com/watch?v= nuCR9WA7_uU. de sabor nacional en su música lo condujo a orientar la producción de un gran número de obras hacia los ritmos de la zona andina, entre otros el extenso trabajo ya mencionado, 300 trozos en el sentimiento popular $^{28}$. El color tonal y el espíritu romántico de este y otros trabajos lo emparentan con el de Emilio Murillo. En esta producción, los dos compositores encuentran sosiego, por lo menos en cuanto a la demanda de sus detractores.

En este ambiente surge Cantar de selva, de Luis E. Nieto, y desde esta perspectiva cobra sentido su creación. Al tomar en cuenta el recuento histórico precedente, resulta entendible que Nieto se diera a la labor de componer una obra en el ambiente del pasillo y recurrir a elementos ajenos a la forma típica. Al igual que Murillo, Nieto utilizó armonías poco convencionales que, más que un recurso expresivo, parecen orientadas a silenciar las acuciantes voces de sus detractores. En Cantar de selva, como ya se dijo, el compositor abunda en el uso de motivos rítmicos, progresiones y bloques sonoros que dejan de lado los temas fluidos característicos de la generalidad de sus obras. No existen evidencias de que, en Pasto, otro compositor de su época realizara trabajos de esta naturaleza, hecho que permite señalar que Cantar de selva es una golondrina solitaria tratando de hacer verano, en los Andes meridionales, en medio de una oscura borrasca; un pasillo intentando encontrar los cauces de la lucha de Murillo: la validación de la obra nacionalista desde la tradición andina. Pasaría algún tiempo antes de que otro compositor nariñense, Javier Fajardo Chaves, encontrara los cauces perdidos del nacionalismo y, desde un punto de vista académico, buscara refrendar los sencillos ritmos populares.

\section{Ecos tardíos}

La composición tradicional en Nariño, que por muchos años había seguido obediente los patrones construidos a lo largo del siglo xIx, sufrirá un duro golpe en las décadas comprendidas entre 1930 y 1960. Los protagonistas de este cambio van a ser, en un comienzo, el disco plano de 75 r.p.m. y, desde la década de los años veinte, la radio. Hasta las calles y veredas de las ciudades y pueblos de la región andina de Nariño llegaron, en un comienzo, las interpretaciones de conocidos cantantes como Enrico

28 Para tener una mejor idea de lo expuesto se recomienda escuchar, entre muchos otros, el trozo Op. 38, No. 44. Disponible en línea: https://www.youtube.com/watch?v=UOIKrp8-8ml. 
Ecos lejanos de una disputa conceptual: el nacionalismo musical en Nariño
MÚSICA, CULTURA Y PENSAMIENTO • NOVIEMBRE 2019

VOL. VIII(8) | 25-44. ISSN- 2145-4728; ISSN-E 2665-2382
Caruso (1873-1921), Tito Schipa (1888-1965), María Barrientos (1884-1946) y Claudia Muzio (1889-1936), entre muchos otros. El disco trajo a Nariño, en la primera mitad del siglo $x x$, sonoridades nuevas: foxtrot, bolero, tango, mambo, porro, cumbia, merecumbé, son, rumba, danzón, montuno, entre otras. Estas músicas fueron validadas por una sociedad que emergía de un condicionamiento moral impuesto por la Iglesia católica desde los tiempos coloniales. La sociedad quería experimentar otras sensaciones, redefinir el cuerpo por medio de un erotismo menos restrictivo y la tradición era una tremenda talanquera a estas expectativas. Sucedió, entonces, que las viejas danzas de pareja suelta fueron desplazadas por las nuevas de pareja cogida, cuyos ritmos sensuales y ligeros dieron más de lo esperado. Pero el disco no logró este prepósito solo, lo hizo con la ayuda de la radio, invento que vio la luz en la década de los veinte y rápidamente se popularizó en todas las regiones del mundo. Para la década de 1930, las ondas hertzianas de estaciones radiales europeas y americanas recorrían la atmósfera llevando todo tipo de mensajes y diversos géneros musicales.

Los aires tropicales ingresaron raudos a los hogares nariñenses y la sociedad entera participó de su consumo. Los intérpretes y compositores se vieron en la situación de seguir en la tradición o acoger los nuevos influjos. Los empresarios de las disqueras y la radio perdieron interés en las viejas músicas, volcando su atención en las de mayor demanda. Muchos instrumentistas acudieron al llamado y cambiaron los patrones conocidos hasta entonces, aprendieron los esquemas rítmico-melódicos y los instrumentos característicos de la nueva música, en especial los de percusión. Aparecen en el panorama regional conjuntos como Jazz Colombia, Alma Nariñense, American Jazz y Jazz Continental, en Pasto; Jazz América, Orquesta Sono Surco, Jazz Capri y Ondas, en Ipiales; Jazz Bolívar, Jazz Calvachi y Orquesta Alma Puerreña, en Puerres; Orquesta Santa Cecilia, en Iles; Amapola del Camino, en Gualmatán; Orquesta Sonora Sinfonía, en Pupiales, entre otros. Los compositores sujetos a la tradición reaccionaron en contra de la música tropical y continuaron escribiendo pasillos y bambucos como un mecanismo de resistencia, pero solo lograron la marginación y el olvido. La música tradicional cedía campo a los aires tropicales y la cumbia y el porro pasaron a ocupar el lugar que antes ocupaba el bambuco. Estos ritmos se difundieron no solo en el territorio nacional, sino también en el latinoamericano y perviven, especialmente la cumbia, en muchos países. A raíz de esta situación, la vieja lucha entre tradicionales y académicos se vistió de un marcado anacronismo y pasó a un segundo plano, podría decirse que quedó reducida a un pequeño grupo de dolientes, aquellos que fueron testigos de lo sucedido.

Distante de este enfrentamiento, en la segunda mitad de la centuria pasada, la música académica en Nariño empezó a dar muestras de existencia. Es difícil de apreciar en su total magnitud, porque algunos aún se encuentran en proceso de producción. Quienes van a ocupar un lugar preponderante en esta nueva fase de la historia regional van a ser Javier Fajardo Chaves (1950-2011) (véase figura3) y Gustavo Parra Arévalo (1963), el primero fallecido prematuramente y el segundo en el pleno ejercicio de sus capacidades intelectuales y anímicas. Los compositores nariñenses nacidos entre 1860 y 1930, salvo los casos de Marceliano Paz Ruiz (1903-1983) y el sacerdote Justino Revelo Obando (1927-2000), construyeron sus obras sobre la base de formas típicas propias de la zona andina colombiana, buscando atender la demanda de una sociedad que estaba aislada del país por sus circunstancias geográficas. Paz Ruiz, por el contrario, compuso siguiendo los cánones estéticos de los compositores preclásicos y desborda su imaginación en la elaboración de complejas obras para la flauta traversa como Diez variaciones para flauta sobre un tema de Adolpho Adam; Revelo Obando, por su parte, desde su formación musical en Roma, dejó un legado de obras corales de corte religioso con sabor tradicional, pero estructuradas desde la estilística de la antigua polifonía.

José Rafael Guerrero (1937), Horacio Mora Ordóñez (1945), José Alfonso Yépez (1953) y Javier Martínez Maya (1964) van a buscar diversas fuentes para la estructuración de sus trabajos: la tradición, los ritmos tropicales y los recursos estéticos de la música académica europea. Yépez, por ejemplo, compuso canciones populares, pero también escribió música orquestal como la Sinfonía en do, en la que revela un buen conocimiento del estilo clásico por su tratamiento melódico-armónico, presente en las pastoriles sinfonías de Haydn. De un modo o de otro, todos estos compositores volvieron sus ojos al viejo baúl de la tradición salvo Parra, cuyo lenguaje está lejos de su influencia directa; la utilización de ciertos patrones rítmicos, en obras como Bámbaros (1999), son solo abstracciones que pueden emparentarlas, en este aspecto con el bambuco, pero no ser necesariamente así. Si se quiere encontrar un deliberado acento en las músicas tradicionales, con fines de 
producir un trabajo nacionalista, hay que auscultar la obra de Fajardo Chaves.

Los vientos del nacionalismo tardío en Europa fueron protagonizados por dos grandes investigadores: los húngaros Zoltán Kodály (1882-1967) y Béla Bartók (1881-1945). Alejándose de la estética del romanticismo y de las vanguardias de finales del siglo xIx y comienzos del xx, construyeron su obra bebiendo de fuentes ignotas, insospechadas y subvaloradas: las músicas campesinas de las aldeas de su país. Recogieron gran número de cantos en los que encontraron pervivencias de los antiguos modos eclesiásticos, la primitiva pentatonía y las complejas heterometrías, extrañas a la composición precedente $y$, obviamente, de difícil ejecución para el músico académico de entonces. Los descubrimientos de estos dos investigadores vigorizaron la música contemporánea y fortalecieron el fundamento epistémico y metodológico para el desarrollo de nuevas disciplinas como la etnomusicología, cuyo objeto de estudio estará, desde entonces, enfocado en estas sonoridades marginales que han acompañado a las comunidades desde tiempos sin memoria. Muchos de los planteamientos de estos compositores se convirtieron en la guía para quienes, con el propósito de nutrir su trabajo creativo, buscaban recursos en las músicas ancestrales.

El trabajo de Fajardo Chaves ${ }^{29}$ refleja muchos de los postulados que Bartók expuso en su texto Estudios sobre música popular (1931). El principal de todos, quizá, es el relativo a la profunda compenetración que el compositor debe tener con el campesinado para poder apropiarse de los elementos más recónditos de su música. Al respecto, sostiene que “... nadie puede sufrir una influencia verdaderamente profunda de parte de la música campesina si no experimenta esta música en el lugar mismo, es decir en comunidad con los campesinos" (Bartók, 1981, p. 91). Fajardo Chaves no ha buscado apropiarse de material temático de la música campesina nariñense para trasladarla a su producción, él interactuó con los músicos de los corregimientos y las veredas

29 Javier Fajardo Chaves nació en Pasto, Nariño, el 22 de mayo de 1950. Inició los estudios de piano bajo la tutela de su madre, la señora Concepción Chaves. Desarrolló labores de docencia musical durante treinta años en la Universidad de Nariño en las áreas de piano, armonía, contrapunto, formas y composición. Su trabajo compositivo supera la doble centena en el que puede encontrarse gran variedad de formatos desde simples bagatelas para piano hasta una ópera. De su copiosa producción se destacan los poemas sinfónicos y la ópera El duende. Su técnica ecléctica combina elementos tradicionales con herramientas propias de la música del siglo xx, especialmente el dodecafonismo. Falleció el 19 de febrero de 2011.

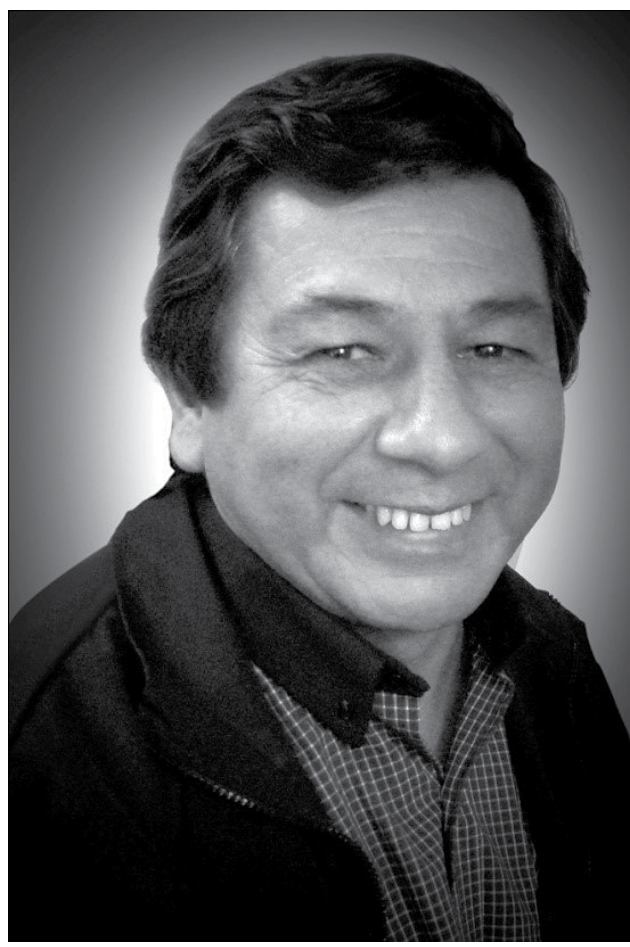

Figura 3. Javier Fajardo Chaves, 2009

Fuente: J. F. Ch.

del municipio de Pasto con el propósito de conocer los fundamentos que la inspiran. En este acercamiento, el compositor captó, en el espíritu de sus interpretaciones y vivencias, sus penas y miedos, lo mismo que sus alegrías, anhelos y esperanzas. Con ese material extraído de la visceralidad más profunda, construyó los momentos festivos, dramáticos, emotivos, reflexivos y melancólicos de su obra. De los grupos musicales, tuvo más contacto con el de Los alegres de Genoy, que por entonces estuvo integrado por Arquímedes Chapal, Felipe Yaqueno, Victoriano Chapal y su director Teodulfo Yaqueno Erazo (1941). Yaqueno es un importante compositor y de su música Fajardo Chaves se apropió de los elementos característicos del ritmo del sonsureño, uno de los más recurrentes en su producción.

Fajado Chaves logró trasvasar el espíritu de la música campesina en su obra en un proceso de sublimación que engrandece las fuentes, lejos de falsearlas o empobrecerlas como fue la constante en muchos lugares de Latinoamérica y Colombia, en la primera mitad del siglo pasado. Bartók dice que “... la música popular alcanza importancia artística solo cuando por obra de un gran talento creador consigue penetrar en la alta música culta y, por lo tanto, influir en ella..." (Bartók, 1981, p. 98), guardando las proporciones respecto de los grandes compositores del siglo $x x$ que se orientaron en esta dirección. Fajardo Chaves 
Ecos lejanos de una disputa conceptual: el nacionalismo musical en Nariño
MÚSICA, CULTURA Y PENSAMIENTO • NOVIEMBRE 2019

VOL. VIII(8) | 25-44. ISSN- 2145-4728; ISSN-E 2665-2382 consiguió este objetivo permitiendo que las sencillas tonadas que resuenan en las afiladas cumbres de los Andes nariñenses, alcancen ciudadanía en el campo de la música académica.

El sonsureño fue el más importante recurso rítmico que Fajardo Chaves utilizó para sus obras. El compás en el que se escribe este ritmo es el de 6/8; sin embargo, su real ejecución muestra la combinación de dicho compás con el de 3/4, situación que permite gran variedad de combinaciones rítmicas. Este ritmo tiene origen en una canción creada por Tomás Burbano Ordóñez hacia 1965, en la que el compositor busca combinar la melancolía característica de los aires andinos con el sabor festivo de la música tropical que, para entonces, había desplazado por completo a la tradición. Dado su dinamismo y característica alegría, es usado por Fajardo en los movimientos conclusivos de muchas de sus obras, por ejemplo, en la Suite colombiana No. 1 para flauta y piano (c. 2002), Noches del Galeras (c. 2017), Danza nariñense, Las lajas (c. 2007), El Tambo (c. 2009), Elegía al educador (c. 2009), Bomboná, Fantasía noches del Tambo, El cuspe (c. 2007), Los cuadros (c. 2008), Tajumbina (c. 2007), Trío para dos saxofones y piano, Fantasía para flauta sola (c. 2009), Mi Nariño para quinteto de cuerdas, Preludio y danza para trompeta y piano, Suite colombiana No. 2 para trompeta y piano, la ópera El duende (c. 2008), Mi tierra (c. 2007), Mi ciudad (c. 2004), entre muchas otras.

Fajardo Chaves utiliza muchos recursos de la tradición colombiana y andina latinoamericana. Hace uso generoso del bambuco, el pasillo, la danza, el vals, el currulao, la cumbia, la contradanza, pero también del sanjuanito, la bomba, el huayno, el yaraví y el bolero, entre otros. La Suite colombiana No. 1 para flauta y piano, por ejemplo, está integrada por cuatro movimientos para los que utiliza aires nacionales: el primer movimiento presenta el material temático en ritmo de contradanza, seguido por un brioso sonsureño que contrasta con la nutrida figuración del primer tema, con el que culmina (véase anexo 2); el segundo movimiento es un bambuco vigoroso, $A B A$, que muestra características propias del bambuco del centro del país; el tercer movimiento es una danza de tema meditativo que expone el solista e intercambia con el piano. La obra finaliza con un allegro en ritmo de sonsureño, llamado por el compositor "aire danzable nariñense" 30 .

30 Fajardo Chaves utilizó diversos denominativos para referirse al sonsureño: aire sureño, bambuco sureño, bambuco pastuso, aire típico nariñense y aire danzable nariñense. Después de una revisión de las obras en las que usa estos nombres, se pudo colegir que se trata del mismo ritmo.
Por último, es importante mencionar que los compositores nuevos, aquellos cuyo natalicio se registra después de 1975, en los que el proceso de creación está aún en pleno desarrollo, también han seguido la línea de la tradición. El ritmo más importante que se refleja en su trabajo es, sin lugar a dudas, el bambuco. Los repertorios derivados de esta última etapa de la historia de la música nariñense están escritos en diferentes formatos, entre los que se destacan: el de banda y los diferentes grupos de cámara. Son algunos de los compositores los siguientes: Carlos René Ordóñez (1975), Edward Zambrano (1975), Ferney Lucero Calvachi (1978), Fausto Adrián Álvarez (1983), Luis Gabriel Mesa (1984), Fernando Carvajal (1986), Cristian Daniel Vallejo (1988), Daniel Andrés López (1988) y Luis Carlos Erazo (1989).

\section{Conclusiones}

En la primera mitad del siglo xx, la composición en Colombia se sumió en las confrontaciones originadas en Bogotá entre músicos tradicionales y académicos, encabezados por Emilio Murillo y Guillermo Uribe Holguín, representantes de una y otra tendencia. Dichas confrontaciones se produjeron a partir de problemas estéticos y conceptuales en los que se hallaban implícitas profundas relaciones de poder que buscaban, fundamentalmente, la imposición de modelos de pensamiento y concepciones educativas en una lucha por el control de las instituciones dedicadas a la enseñanza de la música en el país; además, más allá de esta circunstancia, estuvo la necesidad de preservar intereses de clase e ideologías dominantes.

Mientras Heitor Villa-Lobos (1887-1959), Alberto Ginastera (1916-1983), Carlos Chávez (1899-1978) y Carlos Isamitt (1885-1974), entre otros, estaban estudiando la música autóctona de sus respectivos países con el propósito de sublimarla en la obra académica. En Colombia, algunos académicos también lo hacían, caso de Daniel Zamudio, pero concomitantemente buscaban la argumentación para descalificar las manifestaciones vernáculas que se constituyen en el fundamento de la cultura del pueblo colombiano. Su subvaloración, como ha sido posible verlo en el desarrollo de la música, solo produce atraso y dependencia. Marcelino Menéndez y Pelayo lo dice tajantemente:

Donde no se conserva piadosamente la herencia del pasado pobre o rica, grande o pequeña, no esperemos que brote un pensamiento original ni una vida dominadora. Un pueblo nuevo 
puede improvisarlo todo, menos la cultura intelectual. Un pueblo viejo no puede renunciar a la suya sin extinguir la parte más noble de su vida y caer en una segunda infancia muy próxima a la imbecilidad senil ${ }^{31}$.

La descalificación pública y recurrente de las músicas tradicionales produjo una polarización similar a la vivida por el país en el plano político. La deriva principal de esta confrontación, sin negar que hubiera mucha producción en uno y otro campo, fue la escisión entre la academia y la formación musical informal, cuya debilidad era hallarse desprovista de la racionalidad del método. La confusión conceptual relativa al nacionalismo musical conformó grupos antagónicos, cuya beligerancia fue de tal magnitud que es posible, después de cien años, escuchar los ecos de esos enfrentamientos. No es raro encontrar textos contemporáneos, en los cuales sus autores asumen la defensa de Uribe Holguín, de Valencia o de Murillo. Las voces de quienes observaban periféricamente esta disputa se expresaban del siguiente modo:

Uno de los motivos más poderosos que han influido en la actual decadencia de este arte entre nosotros, es el carácter especial de nuestros músicos. Hay una lepra que se extiende sin cesar entre esta importante clase de la sociedad, y es la rivalidad y desunión en que viven, y que los conducirá a ellos y al arte que profesan a su completa ruina. Sabido es que la unión hace la fuerza y que todo reino que se divide se destruye. Tenemos algunos excelentes profesores y no pocos aficionados; pero en vez de unirse para formar una sola confraternidad, una sola familia, una liga, no ofensiva ni defensiva, sino liga y asociación de trabajo y de estudio, como sucede en los países civilizados, han pretendido formar una especie de federación o desfederación, a manera de lo que sucedió en el orden político (Caicedo, 1978).

Este escrito se publicó originalmente en 1966, en el Semanario de Bogotá, 24 años después de la muerte de Emilio Murillo y se reprodujo en 1978, en un texto compilatorio publicado por el Instituto Colombiano de Cultura (Colcultura), siete años después del fallecimiento de Guillermo Uribe Holguín. De esta situación se colige que los seguidores, tanto de uno

31 Disponible en línea: https://www.mundifrases.com/frases-de/marcelino-menendez-y-pelayo/ (consultada el $1^{\circ}$ de julio de 2018). como de otro, siguieron avivando el fuego de la disputa por muchos años. Así, la pregunta a formularse es: ¿quién ganó?, ante lo que puede contestarse que no hubo ganadores y que la gran perdedora fue la música. Podría decirse que, debido al movimiento de Murillo, algunos repertorios tradicionales perviven en el recuerdo de los colombianos más longevos y que, al igual que en la música académica, buscan espacio en el tumulto sonoro del presente.

En el orden local, si bien el conflicto no revistió las proporciones alcanzadas en el centro del país, la presencia del pasillo Cantar de selva es una pequeña muestra de los ecos que esta disputa nacional tuvo. Luis E. Nieto buscó los hilos de la discordia para alienar su trabajo en defensa de su amigo Emilio Murillo. El pasillo de Nieto se fusiona con los trabajos de madurez del compositor guatecano y los 300 trozos en el sentimiento popular de Uribe Holguín, logrando un momentáneo, aunque frágil acuerdo. La obra de los compositores académicos nariñenses de la segunda mitad del siglo xx, reivindica la música popular colombiana porque la acoge con amabilidad y la sublima en muchos trabajos de gran formato como la ópera El duende, de Javier Fajardo Chaves. Al igual que él, los nuevos compositores, quizá en una remembranza rizomática, están retomando los cauces del nacionalismo para producir su trabajo, buscando, con ello, apuntalar la identidad regional y nacional.

\section{Referencias}

Bastidas, J. M. (2014). Compositores nariñenses de la zona andina, 1860-1917. Pasto: Editorial Universidad de Nariño.

Bartók, B. (1981) Escritos sobre música popular, México: Siglo XXI Editores.

Caicedo, J. (1978). Estado actual de la música en Bogotá. En Greiff, H. de y Feferbaum, D. (eds.). Textos sobre música y folklore. Bogotá: Instituto Colombiano de Cultura.

Cortés, J. (2004). La música popular nacional colombiana. La colección Mundo al día (1924-1938). Bogotá: Universidad Nacional de Colombia, Unibiblos.

Duque, E. (1980). Guillermo Uribe Holguín y sus 300 trozos en el sentimiento popular. Bogotá: Ediciones del Centenario de Guillermo Uribe Holguín. Disponible en http://www.banrepcultural.org/blaavirtual/musica/trozos/inicio.htm. 
Ecos lejanos de una disputa conceptual: el nacionalismo musical en Nariño
MÚSICA, CULTURA Y PENSAMIENTO • NOVIEMBRE 2019

VOL. VIII(8)| 25-44. ISSN- 2145-4728; ISSN-E 2665-2382
Foucault, M. (2010). La arqueología del saber. México: Siglo XXI Editores.

Gómez-Vignes, M. (1991). Imagen y obra de Antonio María Valencia (vol. 2). Cali: Corporación para la Cultura.

Mesa, L. G. (2013). Hacia una reconstrucción del concepto de "músico profesional" en Colombia: antecedentes de la educación musical e institucionalización de la musicología. Tesis doctoral. Universidad de Granada. Disponible en http://digibug.ugr. es/bitstream/10481/29968/1/22503742.pdf.

Ospina, L. (s.f.). Antonio María Valencia: música en cámara. Banco de la República, material audiovisual. Disponible en https://www.youtube. com/watch?v=1520dAbq86U.
Perdomo, J. I. (1980). Historia de la música en Colombia. Bogotá: Plaza y Janés.

Santamaría, C. (2014). Vitrolas, rocolas y radioteatros. Hábitos de escucha de la música popular en Medellín, 1930-1950. Bogotá: Editorial Pontificia Universidad Javeriana.

\section{Materiales en YouTube}

https://www.youtube.com/watch?v=2jCDQAF1DDM https://www.youtube.com/watch?v=nuCR9WA7_uU https://www.youtube.com/watch?v=UOIKrp8-8mI 
Anexo 1. Cantar de Selva, de Luis Eduardo Nieto

\section{CANTAR DE SELVA}

Pasillo

Luis E. Nieto
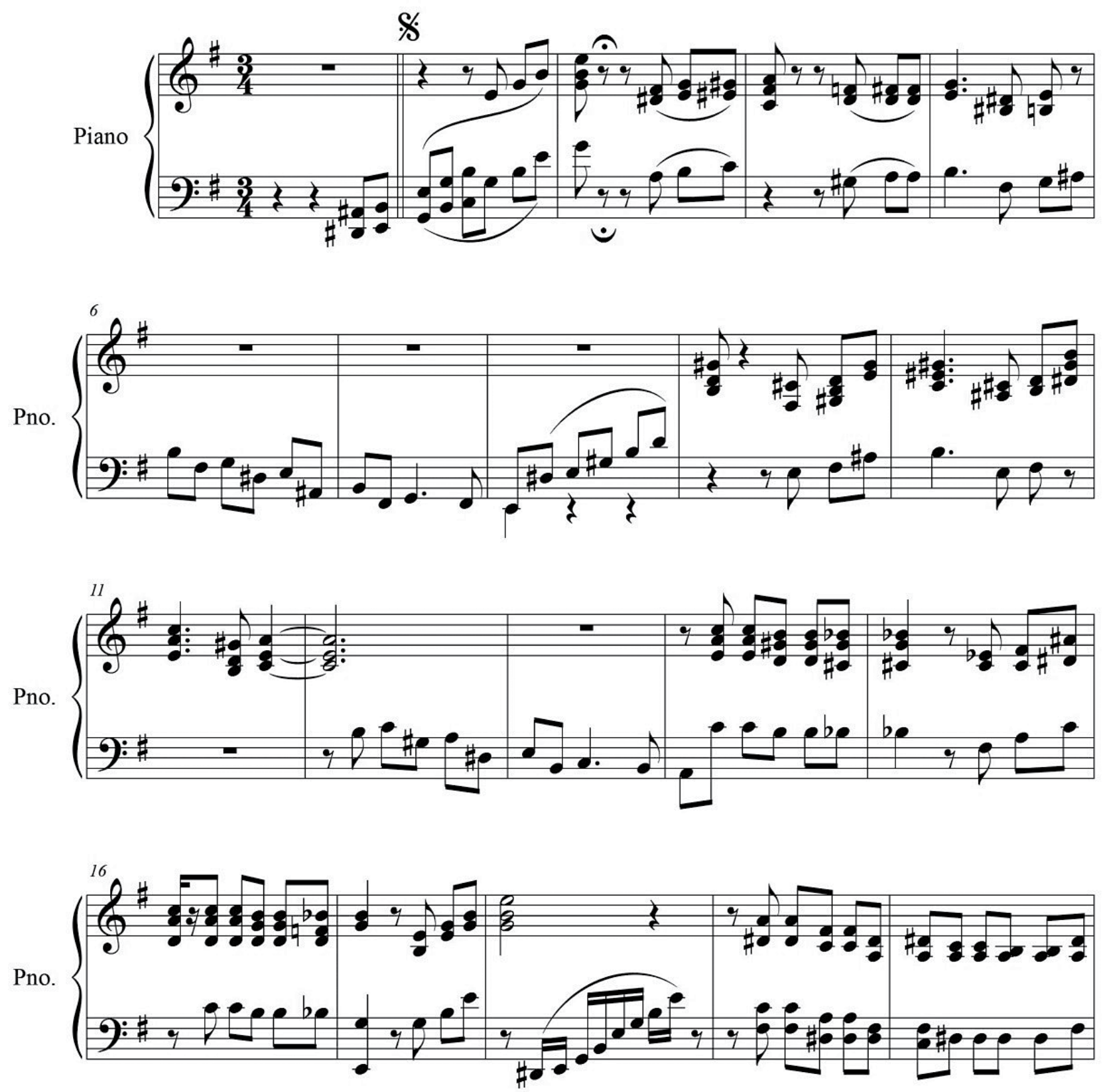

CMenandro Bastidas 
Ecos lejanos de una disputa conceptual: el nacionalismo musical en Nariño
MÚSICA, CULTURA Y PENSAMIENTO • NOVIEMBRE 2019

VOL. VIII(8)| 25-44. ISSN- 2145-4728; ISSN-E 2665-2382
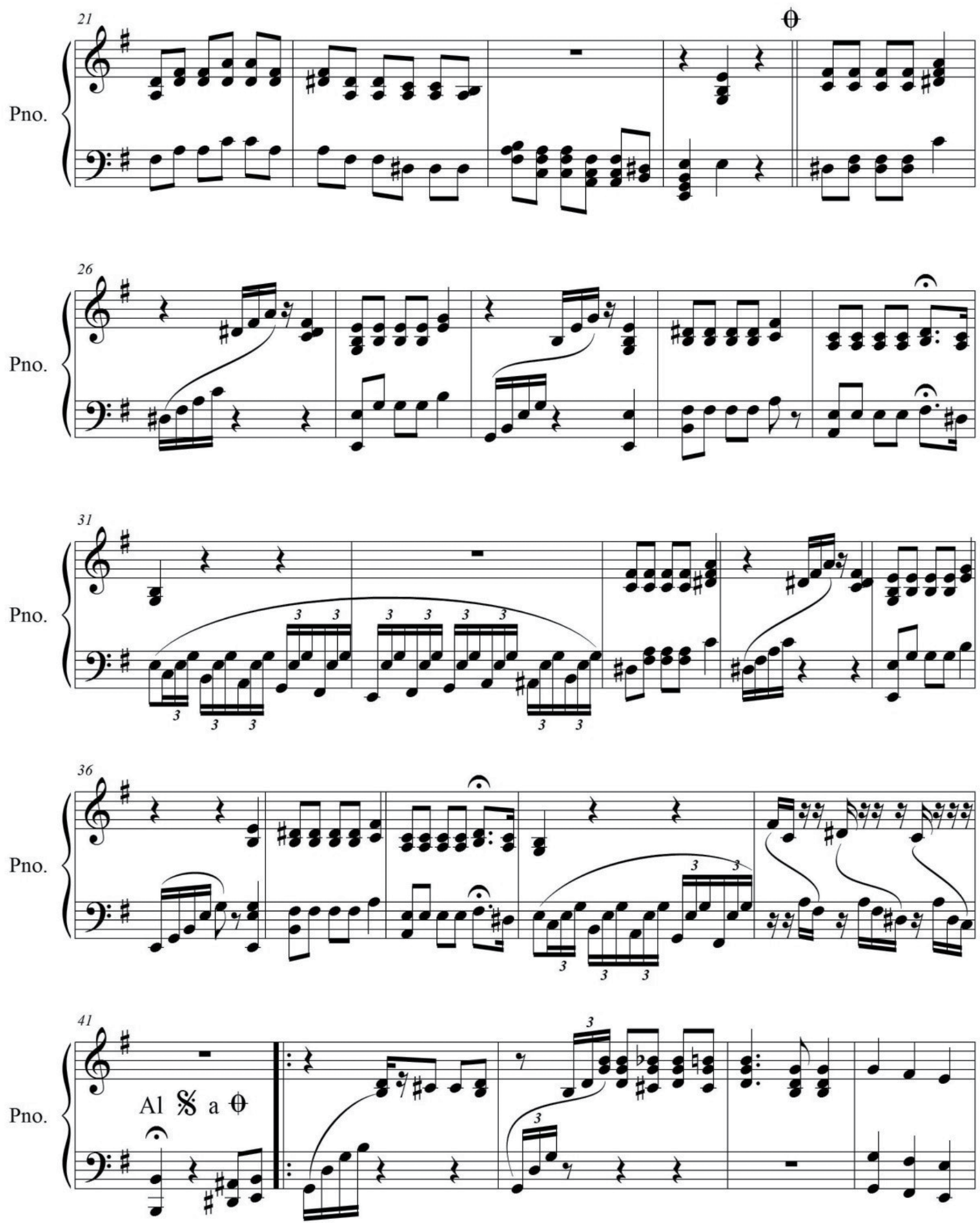

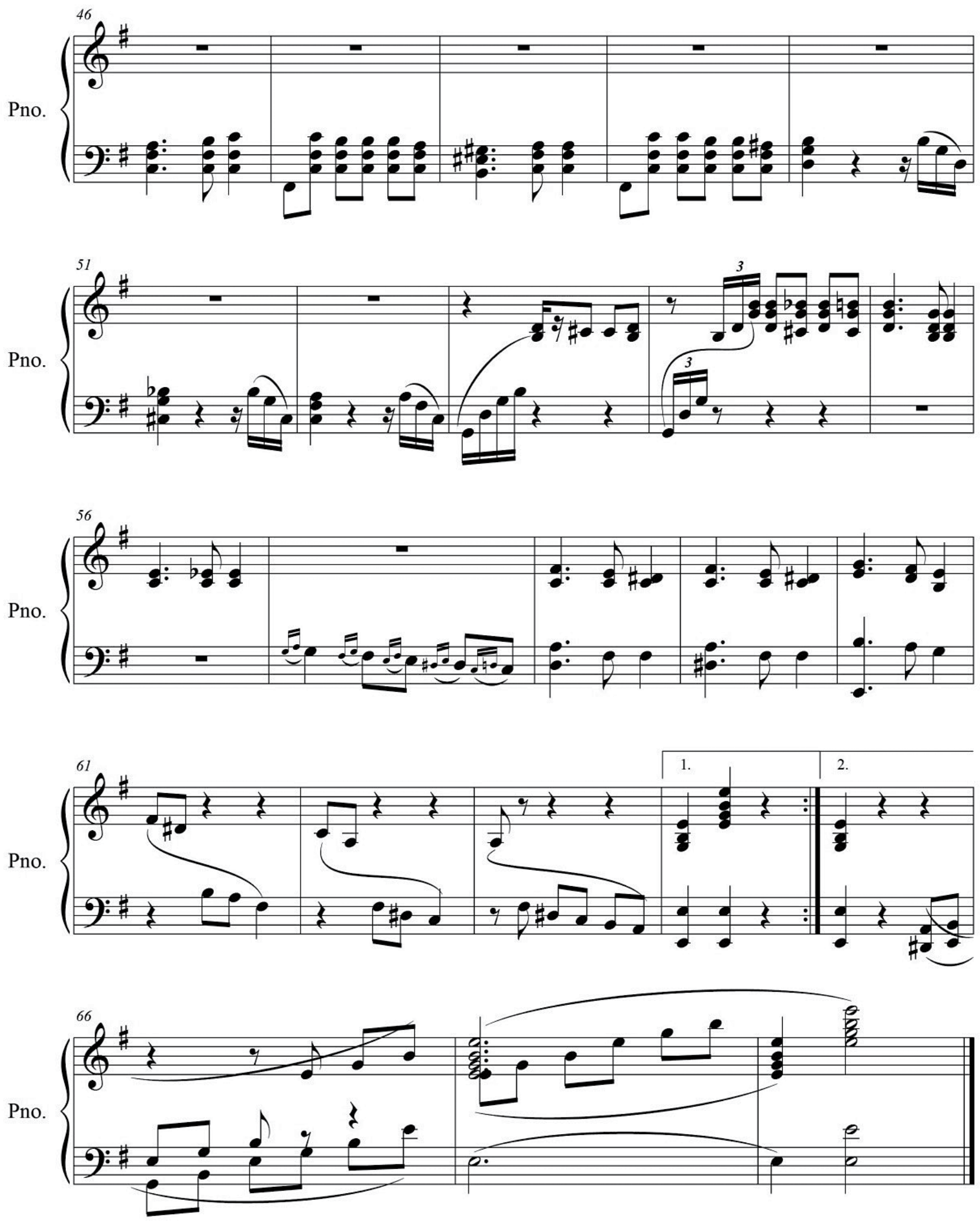
Ecos lejanos de una disputa conceptual: el nacionalismo musical en Nariño
MÚSICA, CULTURA Y PENSAMIENTO • NOVIEMBRE 2019

VOL. VIII(8)| 25-44. ISSN- 2145-4728; ISSN-E 2665-2382

Anexo 2. Suite colombiana No. 1, de Javier Fajardo

\section{SUITE COLOMBIANA No.1 \\ PARA FLAUTA Y PIANO}
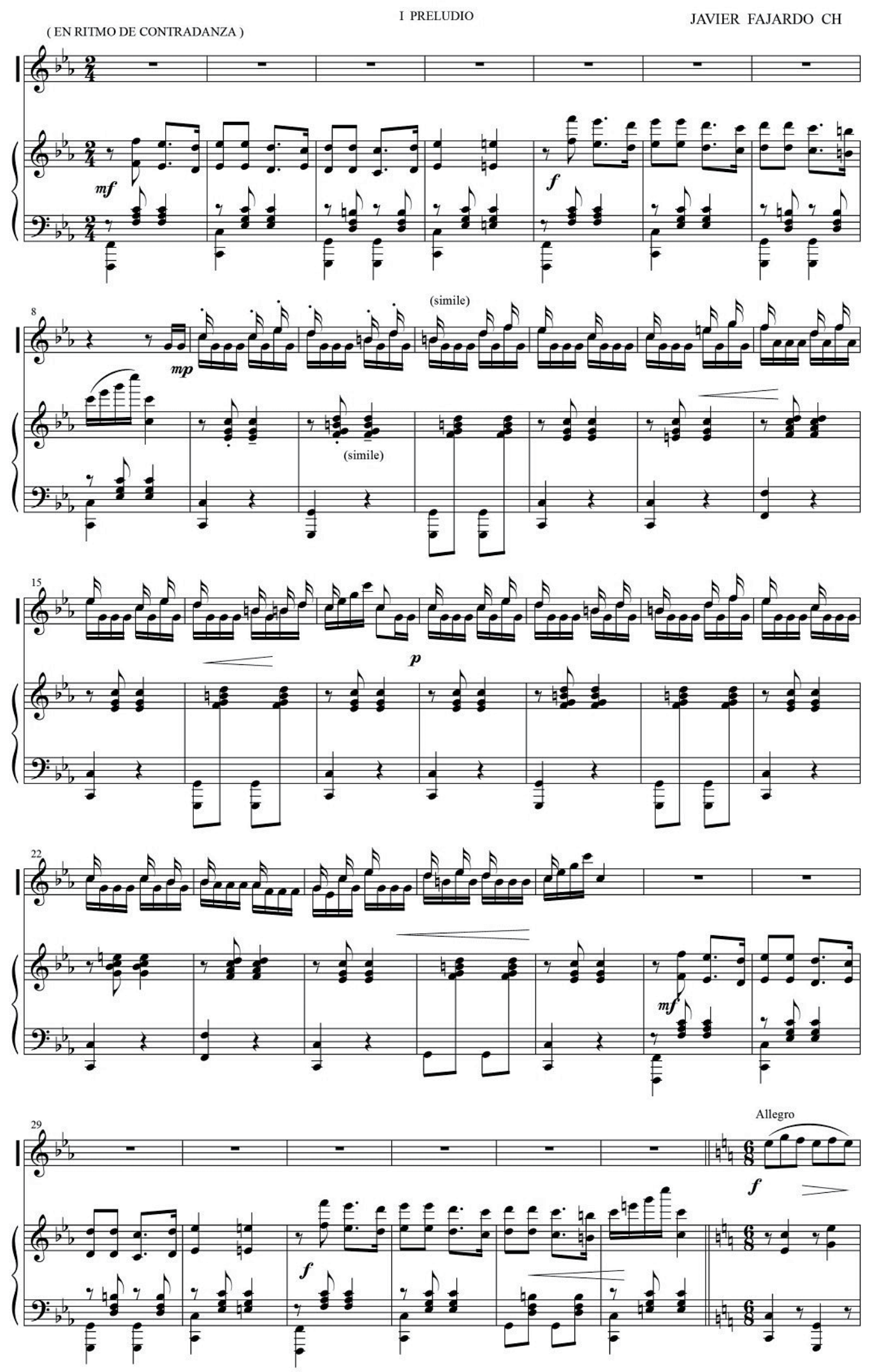

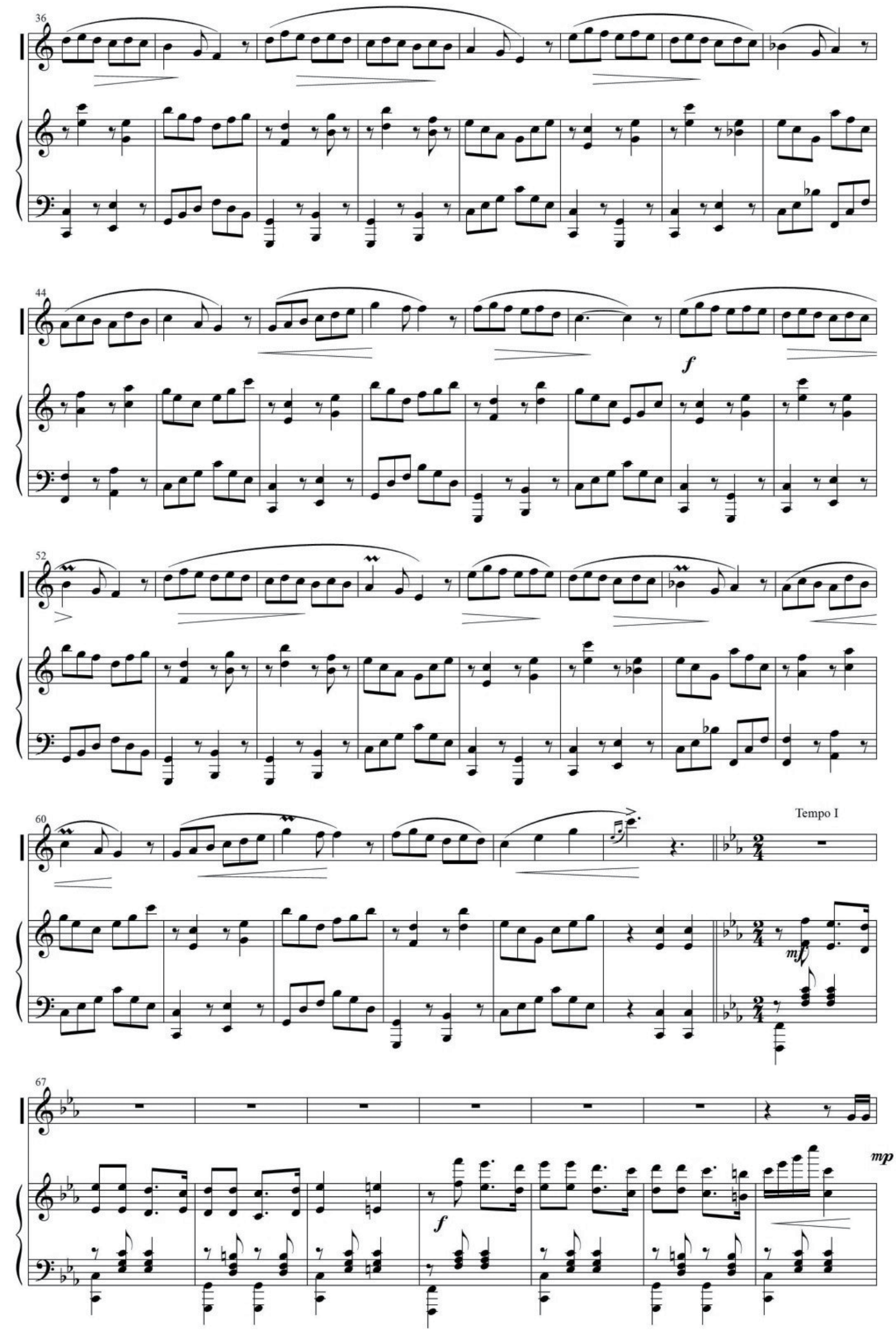
Ecos lejanos de una disputa conceptual: el nacionalismo musical MÚSICA, CULTURA Y PENSAMIENTO • NOVIEMBRE 2019 en Nariño
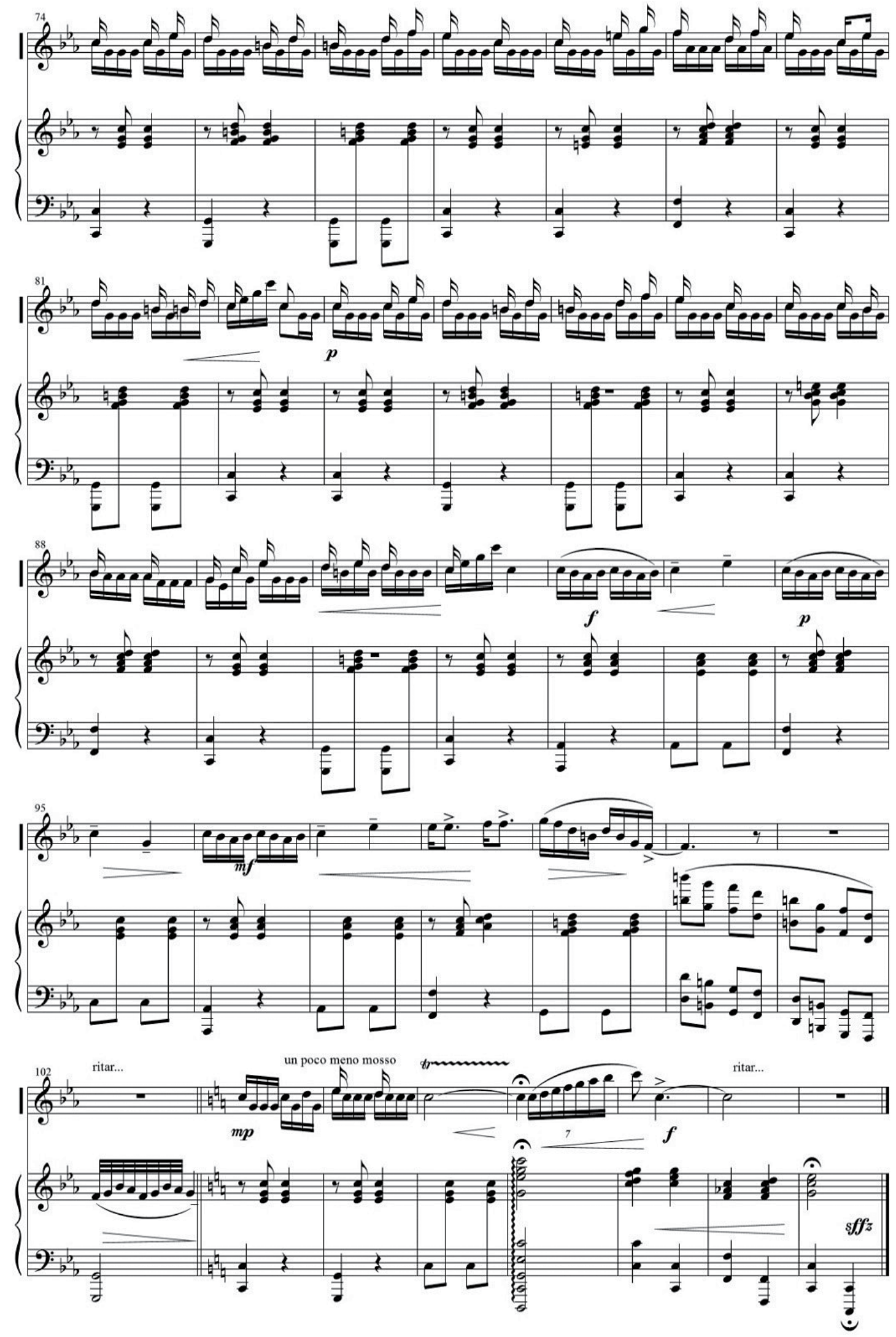
Editorial

\section{Música y cultura}

La Música en México: Reflexiones sobre su historia particular The Music In México: Notes his particular history Alejandro Mercado Villalobos

25 Ecos lejanos de una disputa conceptual: El nacionalismo musical en Nariño Echoes far from a conceptual dispute: Musical Nationalism In Nariño José Menandro Bastidas España

45 Dos Órganos Históricos en Ibagué: Aportes para la contextualización de la tradición organística en Colombia Two historical musical organs in Ibagué: Contributions for the contextualization of the organist tradition in Colombia Nicolás Forero Molano, Mayerlín Alejandra Gómez Guzmán, Julián David Perdomo Rodríguez

63 Evidencias de la recepción del bambuco colombiano en Yucatán. (1908-1920)

Evidences of the colombian bambuco reception in Yucatán (1908-1920)

Claudio Ramírez Uribe

\section{Música y pensamiento}

81

La composición de los Tres Ballets Criollos de Guillermo Uribe Holguín como producto de exportación colombiano para un escenario panamericano

The creation of the Tres Ballets Criollos by Guillermo Uribe Holguín as a Colombian national export product for a

Pan-American scenario

Camilo Vaughan Jurado

93

Métodos y textos adoptados para la enseñanza de música de 1880- 1920 Métodos utilizados en educación informal y métodos para enseñanza de canto en las escuelas

Texts and methods used for music teaching from 1880 to 1920: Methods used in informal education and methods for singing teaching at schools Martha Lucía Barriga

\section{Música, Educación Musical y Género}

104

Identidad, yuxtaposición y resistencia:

tres categorías para entender la música

latinoamericana para piano a comienzos del siglo XX

Identity, juxtaposition and resistance: three categories to understand the Latin-American piano music of the beginning of 20th century

Mónica Tobo Medivelso

Música, educación musical y género.

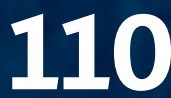
Un estudio sobre la participación de la mujer de la zona andina nariñense en la interpretación (instrumental y vocal), la educación musical y la composición Music, musical education and gender A study on the participation of women in the Andean area of Nariño in the interpretation (instrumental and vocal), music education and composition

Lyda Tobo Mendivelso, José Menandro Bastidas España

\section{Música en clave}

Creación orquestal de la obra para piano Fantasía Romántica de Maruja Hinestrosa

Orchestral creation about Maruja

Hinestrosa's Fantasía Romántica concert for piano and orchestra

Julián Augusto Castro Gaviria,

Anthony Sebastián Chunganá, Andrés Felipe Gómez

\section{Separata}

Fantasía Romántica Sobre Aires Colombianos Concierto para piano y orquesta de Maruja Hinestrosa

Orquestación: Julián Augusto Castro Gaviria

Convocatoria Revista No. 9

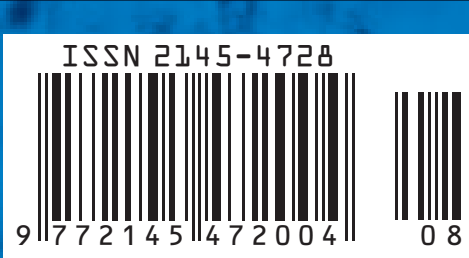

